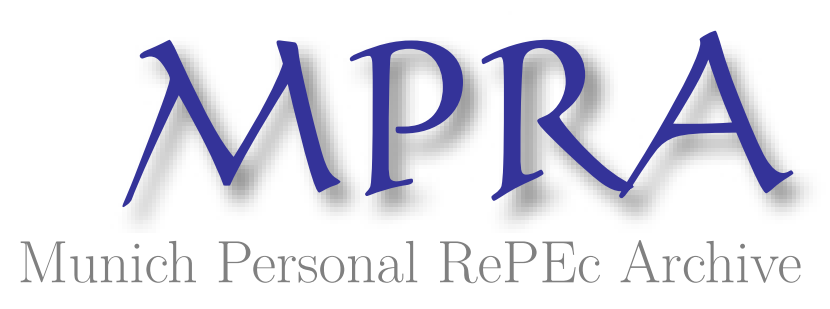

\title{
Within-group heterogeneity and civil war
}

Mizuno, Nobuhiro and Okazawa, Ryosuke

11 April 2015

Online at https://mpra.ub.uni-muenchen.de/63611/

MPRA Paper No. 63611, posted 14 Apr 2015 05:01 UTC 


\title{
Within-Group Heterogeneity and Civil War*
}

\author{
Nobuhiro Mizuno ${ }^{\dagger}$ \\ Faculty of Commerce and Economics, Chiba University of Commerce \\ Ryosuke Okazawa ${ }^{\ddagger}$ \\ Graduate School of Economics, Osaka City University
}

Last Revised: April 11, 2015

\begin{abstract}
This paper provides a bargaining model of conflict in which the government offers a transfer to an opposition group to avoid civil war. Members of the opposition are heterogeneous in income and ideology, and heterogeneity generates disagreement about whether to accept the government's offer. We assume the probability that government's offer avoids conflict increases continuously with the number of opposition group members who agree to accept it. When the within-group heterogeneity is large, the number of members receptive to the government's offer is less responsive to an increase in transfer level. In this situation, the government must raise its transfer substantially to attract support among the opposition. As peace becomes more costly for the government, negotiations are likely to break down.
\end{abstract}

\footnotetext{
*We are grateful to Akihisa Shibata, Kazuhiro Yuki, Naoto Jinji, and the participants of the seminar at the Institute of Developing Economies JETRO and Fukuoka University for their useful comments.

$\dagger^{\dagger}$ E-mail: nobu.mizuno8@gmail.com

‡E-mail: okazawa@econ.osaka-cu.ac.jp
} 


\section{Introduction}

According to Blattman and Miguel (2010), $20 \%$ of the world's countries were engaged in civil war for at least 10 years during 1960-2006. Civil war threatens human rights and welfare and damages economies. ${ }^{1}$

Since the seminal study of Collier and Hoeffler (1998), many studies have found a negative relation between the per capita income and the risk of civil war. ${ }^{2}$ In contrast, most empirical studies find no significant relation between economic inequality and the risk of civil war (Fearon and Laitin 2003, Collier and Hoeffler 2004). However, recent empirical studies cite "within-group" inequality, not overall inequality, as a significant cause of civil war. Using subnational data for sub-Saharan Africa, Østby et al. (2009) find that intra-regional inequality in household assets and education positively affects the onset of a civil conflict. As the failure of negotiations between Israel and Palestine during the 1990s suggests, heterogeneity in ideology within group members also affects the likelihood of conflict. Although Israel-Palestine negotiations began with bilateral popular support, the extremist Palestinian faction Hamas hindered them by attacks against Israel (Kydd and Walter 2002).

This paper presents a bargaining model of a civil conflict that illustrates the manner in which within-group heterogeneity hinders peace negotiations and leads to the outbreak of costly conflicts. Our model follows the standard environment in the literature of bargaining models of conflict. If the government and an opposition group initiate civil war, both bear its cost, but the winner deprives the loser of a portion of its resources. The government has little to gain and much to lose from civil war, and it can thus offers the opposition group transfers to avoid civil war. If the opposition accepts the government's offer, war is avoided. As per Fearon (1995), as long as each group is treated as a unitary player, conflict can be avoided via negotiation because there is no private information, issue indivisibility, or commitment problem.

We extend the standard bargaining model of conflict by introducing heterogeneity in the opposition group and explicitly consider the manner in which conflicting interests among members in the opposing group affect the outcome of bargaining. Income is the opportunity cost of war and ideology is the payoff from waging war (e.x., antagonism toward the government). Due to their heterogeneity, members of the opposition group have different preferences for civil war, and whether the opposition group accepts the government's offer depends on the distribution of members' preferences. Therefore, within-group heterogeneity matters for the outbreak of a civil conflict.

Although many studies treat groups involved in conflict as unitary players,

\footnotetext{
${ }^{1}$ See, for example, Rodrik (1999) and Cerra and Saxena (2008).

${ }^{2}$ Using the quantity of rainfall as an instrument, Miguel et al. (2004) show that poverty exerts causal effects on the risks of civil war.
} 
Jackson and Morelli (2007) analyze a situation wherein the net value of conflict for a pivotal decision-maker differs from that for the entire group. The discrepancy between the pivotal agent's and the group's net values is represented as "political bias" in their paper, and they show that negotiations cannot forestall conflict if the political bias is large.

We present a benchmark model based on an argument similar to that in Jackson and Morelli (2007) to show that extensive within-group income inequality raises the prospect of civil war if the opposition group makes decisions by majority rule. Although our analysis shows the link between within-group heterogeneity and the onset of conflict, the assumption of the majority rule is not plausible in the context of civil war. More importantly, although the benchmark model assumes that only pivotal agents affect the outcomes of a peace process, as the failure of Israel-Palestine negotiations indicates, a faction opposed to peace can derail negotiations.

In the main part of this paper, we consider the likelihood that negotiations are unsuccessful when a faction in one of the negotiating parties opposes peace. Specifically, we assume that the probability of negotiations failing increases continuously as the number of members who reject the government's offer rises. The greater the number of opponents, the greater is their influence on the peace process. Hence, the probability of civil war increases as their number increases.

Under this assumption, we argue that extensive heterogeneity within an opposition group leads to the onset of civil war by the following mechanism. The net payoff to each member of the opposition from accepting the government's offer depends on his/her heterogeneous characteristics, and the payoff increases as the amount offered by the government increases. Government can bolster support for peace by increasing the amount of transfer offered, which can reduce the risk of a civil conflict. However, when heterogeneity within the opposition is large, member preferences are dispersed and the support for the peace process is less responsive to any change in the proposed transfer. Then, the government's marginal cost from increasing support for the peace process increases. In this situation, the government offers the opposition a small transfer, and the equilibrium probability of peace is small. ${ }^{3}$

This paper is related to Esteban and Ray (2011), who show that greater inequalities in within-group income are associated with more intense conflicts. In their model, the poor commit their time to conflicts, whereas the rich contribute money. When the intra-group income inequality is large, the group's poorer members face lower opportunity costs by participating in the conflict and the wealthier members contribute more money to it. However, determining the

\footnotetext{
${ }^{3}$ This mechanism is similar to the probabilistic voting model (Lindbeck and Weibull 1987; Dixit and Londregan 1996; Persson and Tabellini 2000). Mizuno et al. (2012) use a similar mechanism to analyze the relations among inequality, institutions, and growth in a dictatorship.
} 
reason for the opposing groups to undertake costly conflicts exceeds the scope of their analysis.

Understanding the reason behind not being able to avoid costly conflict by negotiation is a major issue in earlier literature, and most studies cite private information and commitment problems as factors underlying failed negotiations (Fearon 1995, Powell 1999, 2002, 2006). The role of transfer (or inclusive policies) to avoid conflict is studied in Azam (1995), Azam and Mesnard (2003), Haimanko et al. (2005), and Reynal-Querol (2005), but these papers neither examine within-group heterogeneity nor do their analyses on the basis of bargaining models.

This paper proceeds as follows. In Section 2, we provide the anecdotal illustrations of peace processes that collapse through internal opposition. In Section 3, we explain our model. In Section 4, we consider the case wherein the opposition group's decision to accept the government's offer is made by a pivotal internal agent. In Section 5, we present the study's primary contribution. In Section 6 , we conclude the study.

\section{Examples of Collapsed Peace Processes}

This study's major findings arise from the primary assumption that peace processes are more likely to collapse under dissension within the opposition group. This assumption reflects that accords between governments and opposition groups can collapse when a faction of members opposes it. This section presents three illustrations supporting this assumption. All three show the significance of within-group heterogeneity in political preferences on outcomes. More importantly, they demonstrate that decisions formalized during negotiations can be overthrown by factions who reject them.

\subsection{Israel and the Palestinian Authority}

Although peaceful resolution to the conflict between Israel and the Palestinian Authority (PA) had been sought during the 1990s, negotiations under the Oslo accords failed. Signed by Israeli Prime Minister Yitzhak Rabin and Yasir Arafat, the leader of the Palestine Liberation Organization (PLO) in 1993, the Oslo accords declared mutual recognition by Israel and the PLO and established a framework for interim self-government in Gaza and the West Bank and finalstatus negotiations.

Although most Israelis and Palestinians welcomed early negotiations, opposition within both camps was strong. Hamas, an opposing Palestinian faction, launched several attacks against Israel to impede negotiations. In particular, attacks after Arafat's 1996 election victory killed 102 people, eroded Israeli 
popular support, and maimed negotiations. This shift in public opinion ousted Israel's Labor government and installed the hawkish Likud government in 1996 and impeded the peace process (Kydd and Walter 2002).

The retrogression of peace indicated Arafat's inability to control internal opposition. Although numerous Palestinians supported him, strong Palestinian opposition revealed "the limits of Arafat's ability to win over the Palestinian street" (Eisenberg and Caplan 2010:216). Obstruction by a violent faction can provoke distrust in negotiating partners and impeding negotiations. As Eisenberg and Caplan (2010:186) note, "The PA's reluctance or inability to crush Hamas and its refusal to extradite Palestinian fugitives to Israel confirmed for many Israelis their presumption that Arafat could not be trusted."

\subsection{Arusha}

The Hutu seized power after Rwandan independence, and many Tutsi fled to escape persecution by the Hutu government. Exiled Tutsi in Uganda formed the Rwanda Patriotic Front (RPF) and invaded Rwanda in 1990. In 1991, Rwanda adopted a multi-party system and the ruling MRNDD Party formed a coalition with former opposition parties, leaving Habyarimana's government substantially controlled by hard-line Hutus. Arusha peace negotiations began in 1992, presided over by moderate Hutu-the members of previous opposition parties and liberals in the MRNDD. Although Habyarimana's government and the RPF signed an accord in August 1993, Hutu hard-liners obstructed its implementation (Clapham 1998). Eventually, according to Clapham (1998:204), "Habyarimana's aircraft was shot down, almost certainly by extremists associated with his own party". After this event, genocide against the Tutsi and moderate Hutu raged on until the RPF seized control of the country.

\subsection{Kashmir}

After 1988, numerous militant groups formed in the Jammu and Kashmir state in India, in which majority population is Muslim, to force the region's merger into Pakistan. The most powerful of those was the Hizbul Mujahideen, supported by Pakistan and the Jamaat-e-Islami political party. Facing military pressure from India, Hizbul Mujahideen began negotiations with India and declared a unilateral ceasefire in 2000 (Staniland 2012). However, negotiations collapsed under opposition from other Pakistani factions. Staniland (2012:29) notes that "Pakistani intelligence services, Kashmiri hard-liners, other jihadi groups, and even the Pakistani Jamaat-e-Islami turned on the Hizb and demanded it pull back from its peace initiative. This pressure on the Hizb and a botched negotiation led it to end its ceasefire after two weeks." 


\section{The Model}

Our model describes an internal conflict between a government and an opposition group. We treat the government as a single entity and the opposition group as a continuum $[0,1]$ of members.

Government initially possesses $W_{G}>0$ quantities of resources (e.x., territory, natural resources, and rents from a political power). The opposition possesses $W_{O} \geq 0$ quantities of resources, which are evenly distributed among its members. ${ }^{4}$

Members of the opposition are heterogeneous with respect to income and the intensity of antagonism toward the government. We denote the income that member $i \in[0,1]$ earns via production as $\alpha_{i}$ and specify that members forfeit an opportunity to earn income if conflict with the government arises. To denote the degrees of antagonism toward the government, member $i \in[0,1]$ receives $\epsilon_{i}$ units of utility when he/she takes up arms.

At the time of peace, opposition member $i$ receives income $\alpha_{i}$. In conflict, he/she receives utility $\epsilon_{i}$. Therefore, we can define the antiwar preferences of member $i$ by $\pi_{i} \equiv \alpha_{i}-\epsilon_{i}$. That is, $\pi_{i}$ represents the degree to which member $i$ prefers peace over conflict. We denote the cumulative distribution function of $\pi_{i}$ as $F(\cdot)$. Without loss of generality, we assume

$$
\forall i, j \in[0,1], \quad i>j \quad \Longrightarrow \quad \pi_{i} \geq \pi_{j} .
$$

We formulate the process of conflict and negotiation as follows. ${ }^{5}$ When at least one group prefers conflict over peace, conflict erupts. ${ }^{6}$ The winner deprives the loser of fraction $D \in(0,1)$ of its resources, but fighting costs both groups fraction $C \in(0,1-D]$ of their own resources. ${ }^{7}$ Therefore, conflict is costly for both. The cost of conflict and the loss from defeat are borne evenly by all members. The probability that the government wins is denoted by $q \in(0,1)$.

Before conflict breaks out, negotiation is available. To avoid conflict, one group can offer the other transfer $T$. Note that positive transfer occurs only if, when there is no transfer, one group prefers conflict and the other prefers peace. As stated below, we consider the case wherein only the government has the incentive to offer transfers. Transfer $T$ can not only be a transfer of resources but also on territory, political concessions, and so on. We assume the resources

\footnotetext{
${ }^{4}$ This assumption of even distribution is not essential, because our model allows heterogeneity in income.

${ }^{5}$ The following formulation is based on Jackson and Morelli (2007) and is similar to many studies on the bargaining model of conflict (See, among others, Fearon (1995), Powell (2002), and Powell (1999)).

${ }^{6}$ The manner in which the decisions by the opposition group members are aggregated into the group-wide decision will be explained below.

${ }^{7}$ We assume $C \leq 1-D$ to ensure that the winner cannot deprive more amounts of the loser's resources than the remaining amounts after conflict.
} 
derived from the government $D W_{G}$ and transfers $T$ are divided evenly among recipients. Government's transfer cannot target a subset of the opposition.

When the government offers transfer $T$, the payoff of the government, $P_{G}(T)$, is given by

$$
P_{G}(T)= \begin{cases}W_{G}-T & \text { if peace. } \\ (1-C) W_{G}-\left[(1-q) D W_{G}-q D W_{O}\right] & \text { if conflict. }\end{cases}
$$

The payoff of member $i$ in the opposition group $P_{i}(T)$ is given by

$$
P_{i}(T)= \begin{cases}W_{O}+T+\alpha_{i} & \text { if peace. } \\ (1-C) W_{O}+\left[(1-q) D W_{G}-q D W_{O}\right]+\epsilon_{i} & \text { if conflict. }\end{cases}
$$

Let $V_{O} \equiv\left[(1-q) W_{G}-q W_{O}\right] D$ denote the expected value of resources transferred from the government to the opposition after conflict.

Concerning the parameters above, we assume the following.

Assumption 1. (Inefficiency of Conflict)

$$
C\left(W_{G}+W_{O}\right)+\bar{\alpha}>\bar{\epsilon},
$$

where $\bar{\alpha}$ and $\bar{\epsilon}$ denote the mean values of $\alpha_{i}$ and $\epsilon_{i}$, respectively.

Assumption 2. If the government makes no transfer, the expected gain of war exceeds its cost for the average member of the opposition group. That is given as follows:

$$
V_{O}+\bar{\epsilon}>C W_{O}+\bar{\alpha}
$$

Assumption 1 means that society's total payoff during peacetime exceeds that during conflict. Assumption 2 means that when there is no transfer, the aggregate payoff to the opposition group from conflict is greater than that in peacetime. Therefore, under Assumption 2, barring any transfer, the opposition chooses war if that decision is made by an agent who maximizes the total payoff to the group. ${ }^{8}$ When both assumptions hold, the government prefers peace with no transfers over conflict. Consider the situation in which negotiation is unavailable; therefore, $T=0$. From Assumption 1, the total payoff to the society is greater under peace. Nevertheless, from Assumption 2, the opposition group receives a larger payoff from conflict. Then, the payoff to government from conflict must be less than the payoff from peace.

Because the government does not wage war when there is no transfer, the opposition group has no incentive to offer transfers. Because, in most cases, only the opposition has an incentive to initiate civil war, these assumptions would be appropriate.

In summary, we consider the following bargaining process:

\footnotetext{
${ }^{8}$ Of course, whether the opposition group decides to wage civil war when $T=0$ depends on the decision making rule.
} 
1. Government offers transfer $T \geq 0$ to the opposition (take-it-or-leave-it offer).

2. The opposition decides whether to accept the offer.

3. If the offer is accepted, the transfer is implemented and civil war is avoided. If rejected, civil war outbreaks.

Because the members of the opposition have heterogeneous preferences, the manner in which each member's decision is aggregated into a group decision is crucial for the equilibrium outcome. The next sections investigate differing aggregations.

\section{Group Decision by a Pivotal Agent}

First, we consider that the group's decision is made by a pivotal decision-maker. We consider two types of pivotal decision-makers. The first is an agent who maximizes the aggregate payoff to the group, whom we call a group welfare maximizer. In this case, heterogeneity within the opposition group does not affect the decision to accept the government's offer. In the absence of private information, issue indivisibility, commitment problems, or political bias, results show that civil war is always avoided by negotiation between the government and the group welfare maximizer (Fearon 1995, Jackson and Morelli 2007).

The second type of pivotal agent is a median voter. In this case, the opposition makes its decision by the majority rule. Distributions of income and ideology in the opposition group can affect the outcome of negotiations. Results show that civil war cannot be avoided by negotiation when the median value of $\pi_{i}$ is sufficiently small. As Jackson and Morelli (2007) argue, a difference of interests between the pivotal agent and the group causes failure of negotiations.

This section assumes a pivotal decision-maker. More importantly, we assume that the members of the opposition honor the agreement between the government and the pivotal decision-maker.

\subsection{Bargaining with a Group Welfare Maximizer}

We assume that the decision of the opposition is made by a group welfare maximizer who maximizes the total payoff of the group. Given the offer $T$, the group welfare maximizer accepts the offer if and only if

$$
W_{O}+T+\int_{0}^{1}\left(\alpha_{i}-\epsilon_{i}\right) d F \geq(1-C) W_{O}+V_{O} .
$$

This condition can be rewritten as

$$
T \geq T_{G W} \equiv V_{O}-C W_{O}+\bar{\epsilon}-\bar{\alpha} .
$$


From Assumption 2, $T_{G W}>0$.

Anticipating the behavior of the group welfare maximizer, the government offers a transfer in the amount that maximizes its payoff:

$$
P_{G}(T)= \begin{cases}W_{G}-T & \text { if } T \geq T_{G W} \\ (1-C) W_{G}-V_{O} & \text { otherwise }\end{cases}
$$

From (5) and (6), we get the following proposition.

Proposition 1. Let Assumptions 1 and 2 hold. Assume that the decision of the opposition group is made by the group welfare maximizer. Then,

- Civil war is always avoided by negotiation.

- The government transfers the $T_{G W}$ of its resources to the opposition.

Proof. See Appendix.

The intuition behind Proposition 1 is as follows. Consider the payoff to the government by offering transfer $T \geq T_{G W}$ to avoid war. Since government seeks an agreement that minimizes transfers, it offers $T=T_{G W}$. Then, the payoff to the opposition group under the agreement is the same as that under conflict. From Assumption 1, peace increases the society's total payoff. This means that the government receives a larger payoff by offering $T=T_{G W}$ than by accepting civil war. Because conflict is socially inefficient, negotiations between the government and the group welfare maximizer can avoid it.

\subsection{Bargaining with the Median Voter}

Assume that the opposition group's decision is made by the median agent who has the median value of $\pi_{i}$. In this situation, the majority rule determines the opposition group's collective decision. Let $\pi_{m}$ denote the median value of $\pi_{i}$. Then, the median agent accepts the offer $T$ if and only if

$$
W_{O}+T+\alpha_{m} \geq(1-C) W_{O}+V_{O}+\epsilon_{m} .
$$

This condition can be rewritten as

$$
T \geq T_{M} \equiv V_{O}-C W_{O}+\epsilon_{m}-\alpha_{m} .
$$

Anticipating the median agent's behavior, government offers $T$ to maximize its payoff:

$$
P_{G}(T)= \begin{cases}W_{G}-T & \text { if } T \geq T_{M} \\ (1-C) W_{G}-V_{O} & \text { otherwise. }\end{cases}
$$


The difference between this case and that involving the group welfare maximizer is the amount of the transfer government must offer to avoid conflict. To persuade the median agent, the government must provide a transfer at least equal to $T_{M}$. Since $T_{M}$ can be written as

$$
T_{M}=T_{G W}+\bar{\pi}-\pi_{m},
$$

the larger the degree by which $\pi_{m}$ falls below $\bar{\pi}$, the larger the transfer government must provide to avoid conflict compared with the case of group welfare maximizer. When the median agent substantially prefers conflict over peace, the government's cost to avoid conflict is very large. Therefore, if $\pi_{m}$ is sufficiently small, government prefers civil war to avoiding it by providing transfer $T_{M}$.

When $\pi_{m} \geq \bar{\pi}$, the transfer government must offer to avoid conflict does not exceed that which it must offer the group welfare maximizer. Therefore, in this case, civil war is always avoided by negotiation.

Proposition 2. Let Assumptions 1 and 2 hold. Assume the opposition group's decision is made by the median agent. Then,

- When $\pi_{m} \geq \bar{\pi}$, civil war is always avoided by negotiation and the government provides transfer $T_{M}$.

- When $\pi_{m}<-C\left(W_{O}+W_{G}\right)$, civil war cannot be avoided by negotiation.

- Civil war is likely in these situations:

- The median agent earns low income in peacetime $\left(\alpha_{m}\right.$ is small) and obtains a large ideological payoff from war $\left(\epsilon_{m}\right.$ is large).

- Resources of each group, $W_{G}$ and $W_{O}$, are small.

- The cost of conflict $C$ is small.

Proof. See Appendix.

Although civil war is always avoided by negotiation if the pivotal agent is a group welfare maximizer, negotiation fails when the pivotal agent is the median agent and his/her net payoff from conflict is sufficiently large.

Proposition 2 implies that civil war is likely if within-group income inequality is large. Given the aggregate (average) level of income $\bar{\alpha}$, large within-group income inequality reduces median income $\alpha_{m}$ and leads to smaller values of $\pi_{m}$. In such a case, the median agent substantially prefers conflict over peace because his/her opportunity cost of conflict is small. Because government must persuade the median agent by offering a large transfer, it prefers civil war over a peaceful settlement. 
The above discussion presents one explanation for the positive relation between within-group income inequality and civil war. However, the assumption of majority rule may be inappropriate in the context of civil war for decisions by opposition groups are not necessarily determined democratically. Section 5 considers a different formulation that associates decisions by each member of the opposition group with the outcome of peace negotiations. It reflects the lack of disciplined decision-making in the opposition group and provides another mechanism linking within-group heterogeneity to the outbreak of civil war.

\section{$5 \quad$ Uncertainty about Negotiated Outcomes and Heterogeneity}

In Section 4, members of the opposition group were assumed to honor the agreement between the delegates of the two groups. Thus the prior analysis supposes a disciplined opposition whose members conform to the leader's decisions. However, as examples in Section 2 illustrate, the elements of either or both parties can hinder peace even if their delegates push negotiations. Taking these considerations into account, we abandon the assumption that avoiding conflict through negotiation depends on a pivotal decision-maker. Instead, we assume the likelihood that the peace process collapses under disagreement by some members of the opposition. This assumption reflects that the peace process can collapse if members oppose the government's offer and that collapse is more likely when opposition is vigorous. This section analyzes how within-group heterogeneity affects the occurrence of civil war in this environment.

\subsection{Probability of Completing a Deal}

Consider that the outcome of negotiations is uncertain. As per Section 2, the process can collapse when a faction within the opposition disavows the agreement its delegate has signed. We describe these situations as follows.

Let $n$ be the number of members of the opposition who accept the government's offer. Let $p(n)$ be the probability that the government's offer is accepted and civil war is avoided when $n$ members agree to it. Naturally, $p(0)=0$ and $p(1)=1$.

We also assume that $p(n)$ is continuously differentiable and that $p^{\prime}>0$. The larger the number of opponents, the larger is the effect of their actions. Thus, the likelihood the peace process avoids conflict $[p(n)]$ increases with the number of members who support it $(n)$.

Note that government confronts the positive probability of civil war when elements within the opposition reject its offer. If the median agent is the pivotal agent and all members honor the majority's decision as in Section 4.2, $p(n)=1$ 
if $n>\frac{1}{2}$ and $p(n)=0$ otherwise. However, if the process can collapse when a faction rejects the government's offer, there is a positive likelihood negotiations will collapse although the majority accedes.

We can imagine numerous scenarios in which factions opposed to peace derail negotiations. For example, attacks by dissidents engender hawkish reactions by the government, as was the case between Israel and the PA. Alternatively, powerful dissidents may seize the initiative from dovish factions, as the cases of Arusha and Kashmir indicate.

Concerning probability $p(n)$, we assume the following:

Assumption 3. We assume $p(n)$ is continuously differentiable and satisfies $p^{\prime}>0, p^{\prime \prime} \leq 0, p(0)=0$, and $p(1)=1$. Moreover, we assume the elasticity of $p(n)$ with respect to $n$ is constant. That is

$$
\forall n \in[0,1] \quad \frac{p^{\prime}(n) n}{p(n)}=\sigma .
$$

We assume constant elasticity to simplify the analysis and derive a unique analytical solution. The assumption is not essential for our main results.

\subsection{Equilibrium}

We assume the following uniform distribution for $\pi_{i}$ :

Assumption 4. The distribution of $\pi$ is given by

$$
\pi_{i} \sim U\left[\bar{\pi}-\frac{\xi}{2}, \bar{\pi}+\frac{\xi}{2}\right], \quad \xi>0
$$

The density of the distribution is $1 / \xi$. Parameter $\xi$ represents the degree of heterogeneity among the members of the opposition. Larger values for $\xi$ indicate greater heterogeneity within the opposition group.

After observing the government's offer $T$, each member of the opposition decides whether to accept it. When $n$ members agree, negotiations forestall civil war with probability $p(n)$.

Opposition member $i \in[0,1]$ agrees with the offer if and only if

$$
W_{O}+T+\alpha_{i} \geq(1-C) W_{O}+V_{O}+\epsilon_{i} .
$$

This can be written as

$$
\pi_{i} \geq \tilde{\pi}(T) \equiv V_{O}-C W_{O}-T,
$$

where $\tilde{\pi}(T)$ represents the threshold value of the antiwar stance when the government offers $T$. Thus, all members with $\pi_{i} \geq \tilde{\pi}(T)$ accept offer $T$ and others do not.

Since member $i=1$ has the largest value of $\pi, \pi_{1}$ equals $\bar{\pi}+\xi / 2$. Similarly, $\pi_{0}$ equals $\bar{\pi}-\xi / 2$. To simplify the analysis, we assume the following: 
Assumption 5. Some members of the opposition prefer peace over conflict irrespective of a government transfer. That is,

$$
\tilde{\pi}(0)=V_{O}-C W_{O} \leq \bar{\pi}+\xi / 2=\pi_{1} .
$$

Under Assumption 5, some members of the opposition always prefer peace. Since $\bar{\pi}<\tilde{\pi}(0)$ from Assumption 2, the majority in the opposition prefers conflict if the government offers no transfer.

Let $n(T)$ be the number of members who accept government's offer $T$. Because all members with $\pi_{i} \geq \tilde{\pi}(T)$ accept $T$, from (12), $n(T)$ can be written as

$$
\begin{aligned}
n(T) & =\int_{\tilde{\pi}(T)}^{\pi_{1}} \frac{1}{\xi} d \pi \\
& =\min \left\{\frac{1}{\xi}\left[\bar{\pi}+\frac{\xi}{2}-\left(V_{O}-C W_{O}-T\right)\right], 1\right\} .
\end{aligned}
$$

From (13), we derive the number of opposition members who accept the offer $T=0$ as

$$
n_{0} \equiv n(0)=\frac{1}{\xi}\left[\bar{\pi}+\frac{\xi}{2}-V_{O}+C W_{O}\right] \geq 0 .
$$

If the government's offer satisfies $\tilde{\pi}(T) \leq \pi_{0}$, all members of the opposition accept it and $n(T)=1$. Clearly, offering $\tilde{\pi}(T)<\pi_{0}$ is suboptimal for government because it can reduce the amount of its transfers without losing opposition support. Therefore, we consider that $\tilde{\pi}(T) \geq \pi_{0}$ in the following.

Equation (13) shows an important property of the relation between transfers and support for peace. When the amount of the transfer increases, threshold $\tilde{\pi}(T)$ decreases and the number of members receptive to the offer increases. Further, the marginal effect of the transfer on the number of supporters $(n)$ is inverse to the degree of heterogeneity, as $n^{\prime}(T)=1 / \xi$. Figure 1 shows why its marginal effect is small when heterogeneity is great. When heterogeneity within the opposition is large, the density of the distribution of $\pi_{i}$ is small and the shift of $\tilde{\pi}(T)$ resulting from an increase in $T$ does not significantly increase support for the offer. Therefore, support for the government's offer is less responsive to an increase of transfer when the opposition is more heterogeneous. ${ }^{9}$

From (13), we derive the function $T(n)$, which represents the transfer amount necessary to convince that $n$ members of the opposition accept the offer as

$$
T(n)=\xi n+V_{O}-C W_{O}-\left(\bar{\pi}+\frac{\xi}{2}\right), n \geq n(0) .
$$

\footnotetext{
${ }^{9}$ This mechanism resembles the probabilistic voting model. See Lindbeck and Weibull (1987), Dixit and Londregan (1996), and Persson and Tabellini (2000). Mizuno et al. (2012) use a similar mechanism to analyze the relation between inequality and institutions in a dictatorship.
} 


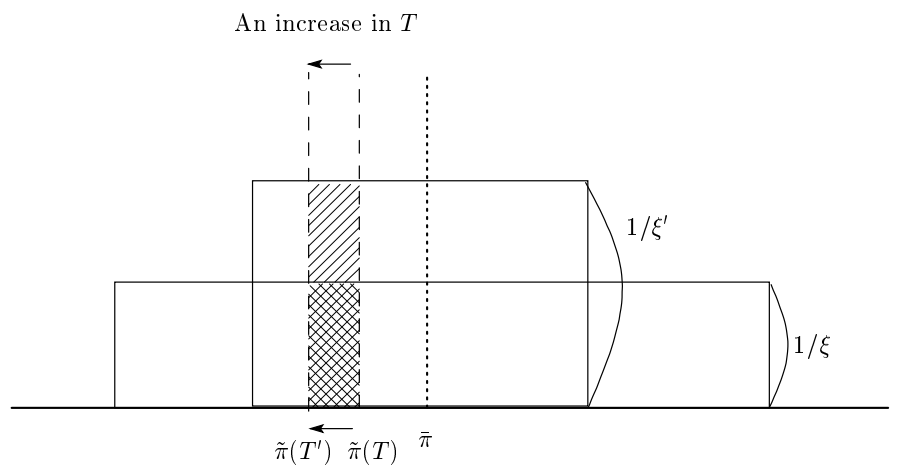

Figure 1: The marginal effect of transfer

Following similar logic, the necessary increment in transfer needed to secure a marginal increase in $n$ is increasing in $\xi$ as $T^{\prime}(n)=\xi$. When heterogeneity among the opposition $(\xi)$ is large, the effect of $T$ on $n$ is small, and government must increase $T$ significantly to secure a definite increase in $n$. Note that $T(n)$ is increasing in $V_{O}$ and decreasing in $C W_{O}$ and $\bar{\pi}$. This is because the value of conflict for the opposition is increasing in $V_{O}$ and decreasing in $C W_{O}$ and $\bar{\pi}$. Therefore, government must offer a large transfer to gain support in these situations.

Anticipating the opposition's decision, government determines the amount of its proposed transfer to maximize its expected payoff. Using function $T(n)$, government's objective function can be written as:

$$
p(n)\left[W_{G}-T(n)\right]+(1-p(n))\left[(1-C) W_{G}-V_{O}\right]
$$

We define $R(n) \equiv C W_{G}+V_{O}-T(n)$ as government's peace surplus. When $n$ is large, government offers a large transfer, and its peace surplus is small. Using function $R(n)$, government's problem can be written as:

$$
\begin{aligned}
& \max _{n \in\left[n_{0}, 1\right]} p(n) R(n)+(1-C) W_{G}-V_{O} \\
& \text { subject to }(15) .
\end{aligned}
$$

Let $n^{*}$ be the equilibrium number of opposition group members who accept the government's offer. We assume $n^{*}>n_{0}$. From the first-order condition, $n^{*}$ satisfies:

$$
p^{\prime}\left(n^{*}\right) R\left(n^{*}\right)-p\left(n^{*}\right) T^{\prime}\left(n^{*}\right) \geq 0 \quad \text { with equality when } n^{*}<1 \text {. }
$$

Government faces a trade-off between the risk of civil war and the size of its 


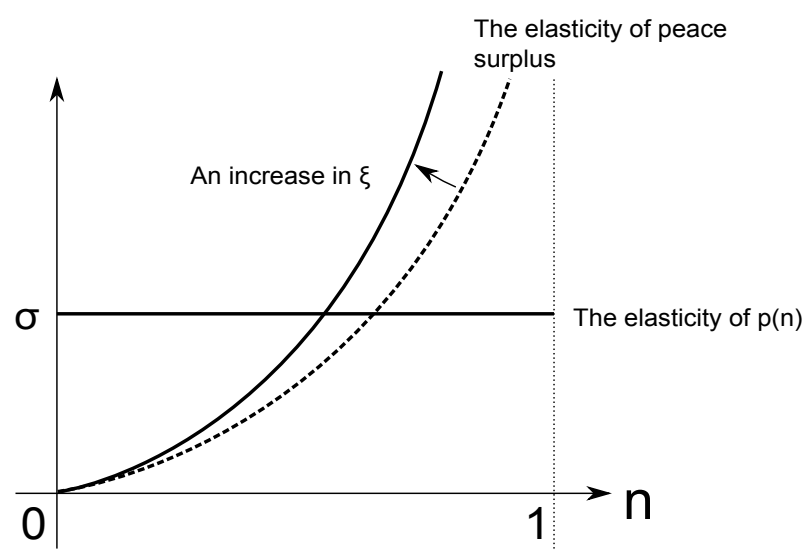

Figure 2: The negative relationship between $n^{*}$ and $\xi$

peace surplus. ${ }^{10}$ An increase in opposition support for its offer reduces the risk of war, but the larger transfer needed to obtain it reduces peace surplus. The first term in (17) is the marginal benefit of increasing $n$ and the second term is the marginal cost. Because $T\left(n_{0}\right)=0$, government's peace surplus when it offers no transfer is $R\left(n_{0}\right)=V_{O}+C W_{G}$, which is positive from Assumptions 1 and 2. This means $R\left(n^{*}\right)>0,{ }^{11}$ and condition (17) can be rewritten as

$$
\frac{p^{\prime}\left(n^{*}\right) n^{*}}{p\left(n^{*}\right)}=\sigma \geq \frac{\xi n^{*}}{C\left(W_{G}+W_{O}\right)+\bar{\pi}+\xi / 2-\xi n^{*}}=-\frac{R^{\prime}\left(n^{*}\right) n^{*}}{R\left(n^{*}\right)} .
$$

The LHS is the elasticity of the probability $p(n)$, which equals constant $\sigma$ from Assumption 3. The RHS is the elasticity of government's peace surplus with respect to $n$. Since government maximizes the product of $p(n)$ and $R(n)$, it equalizes these two elasticities.

From (18), we solve for $n^{*}$ as

$$
n^{*}=\min \left\{1, \frac{\sigma}{(1+\sigma) \xi}\left[C\left(W_{G}+W_{O}\right)+\bar{\pi}+\frac{\xi}{2}\right]\right\} .
$$

When within-group heterogeneity among the opposition $(\xi)$ is large, $n^{*}$ is small and the probability of civil war $\left[1-p\left(n^{*}\right)\right]$ is large. Figure 2 illustrates the relation between $\xi$ and $n^{*}$.

\footnotetext{
${ }^{10}$ Similar risk-return trade-offs appear in the bargaining model of conflict with asymmetric information (see Powell 1999). In a model featuring asymmetric information, the probability of peace is less responsive to the change in transfer amounts when there is great uncertainty about the opponent's military technology. In contrast, this study shows that support for peace negotiations is less responsive to a change in transfer amounts when within-group heterogeneity is large.

${ }^{11}$ Since $R\left(n_{0}\right)>0, p^{\prime}>0$, and $p\left(n_{0}\right) R\left(n_{0}\right) \geq 0, p(n) R(n)$ takes a positive value if $n$ is sufficiently close to $n_{0}$. Thus, making $p(n) R(n)$ negative is suboptimal for the government.
} 

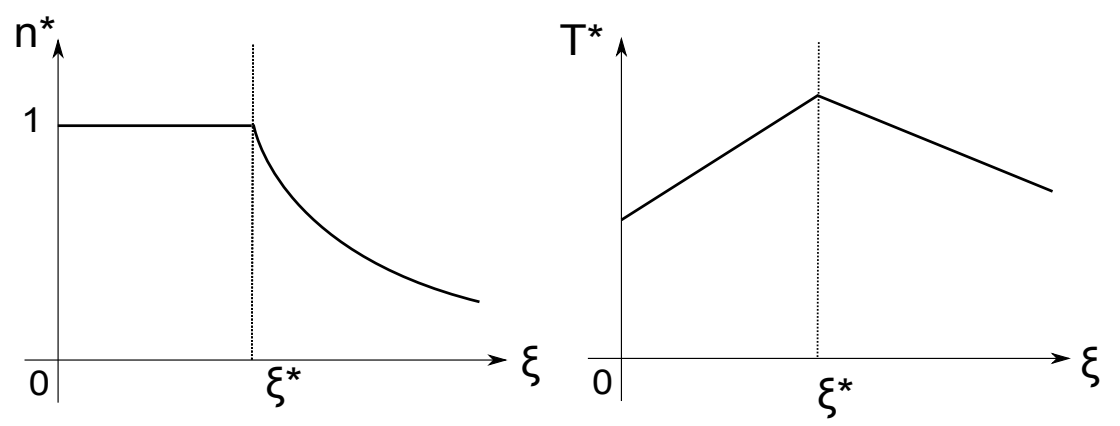

Figure 3: The graph of $n^{*}$ and $T^{*}$.

Since $T^{\prime}(n)$ is increasing in $\xi$, high degrees of heterogeneity imply that the government must increase transfers substantially to secure a marginal increase in $n$. Because of this effect, the elasticity of the peace surplus is increasing in $\xi$. That is, the peace surplus declines sharply as $n$ rises when heterogeneity within the opposition is large. Therefore, an increase in $\xi$ shifts the graph of the elasticity of the peace surplus upward in Figure 2. Because the elasticity of the probability $p(n)$ is assumed to be constant and independent of $\xi$, the increase in $\xi$ reduces the level of $n^{*}$, as shown in Figure 2. ${ }^{12}$

The equilibrium number of opposition group members who support government's offer $\left(n^{*}\right)$ increases with the cost of conflict $C\left(W_{G}+W_{O}\right)+\bar{\pi}$ and $\sigma$ (the elasticity of $p$ ). The result is intuitive that an increase in the cost of conflict reduces the risk of war. A large elasticity of $p$ implies that negotiation by transfer is more effective. Hence an increase in $\sigma$ reduces the risk of war.

From (15) and (19), we solve for the equilibrium level of transfer offered by the government as

$$
\begin{aligned}
T^{*}=\min \left\{V_{O}-C W_{O}-\left(\bar{\pi}-\frac{\xi}{2}\right),\right. \\
\left.V_{O}+\frac{1}{1+\sigma}\left[C\left(\sigma W_{G}-W_{O}\right)-\left(\bar{\pi}+\frac{\xi}{2}\right)\right]\right\} .
\end{aligned}
$$

The relation between $T^{*}$ and $\xi$ is non-monotonic, as described in Figure 3. When the within-group heterogeneity $\xi$ is sufficiently small, it is optimal for the government to win over all opposition group members. In this case, an increase in $\xi$ increases the amount of the transfer needed to win over the member

\footnotetext{
${ }^{12}$ Assuming constant elasticity of $p(n)$ is not crucial for our argument. Even if the elasticity of $p(n)$ depends on $n$, an increase in $\xi$ shifts the graph of elasticity of the peace surplus upward but does not change the graph of the elasticity of $p(n)$. Therefore, $n^{*}$ would decrease as heterogeneity in the opposition group increases as long as interior solution is guaranteed.
} 
who most prefers conflict. The transfer, therefore, is increasing in $\xi$ when $\xi$ is sufficiently small $\left(\xi<\xi^{*}\right.$ in Figure 3$)$.

When within-group heterogeneity $\xi$ is sufficiently large $\left(\xi>\xi^{*}\right.$ in Figure 3$)$, $n^{*}$ is an interior solution (i.e., $n^{*}<1$ ) and decreasing in $\xi$ as explained above. Due to this effect, $T^{*}$ is decreasing in $\xi$ in this case.

The above argument can be summarized as the following proposition:

Proposition 3. Let Assumptions 1-5 hold. We also assume the probability that civil war is avoided by negotiation is represented by the function $p(n)$. In the case of the interior solution $\left(n^{*}<1\right)$, the following results hold:

- Opposition support for government's offer is decreasing in the within-group heterogeneity (i.e., $n^{*}$ is decreasing in $\xi$ ). The risk of civil war $1-p\left(n^{*}\right)$ is therefore increasing in $\xi$.

- The risk of civil war is small when the cost of conflict $C\left(W_{G}+W_{O}\right)+\bar{\pi}$ is large.

- The risk of civil war is small when elasticity $\sigma$ is large.

When we consider the corner solution $\left(n^{*}=1\right)$, the following result also holds:

- The relation between the transfer offered by government $\left(T^{*}\right)$ and $\xi$ takes an inverted- $U$ shape.

Proposition 3 says that within-group heterogeneity increases the risk of civil war because it makes government transfers a less effective tools to avoid conflict. Our model provides a possible explanation for the empirical finding that intra-regional inequality relates positively to the risk of civil conflict. Moreover, it helps to understand why peace processes collapse when within-group heterogeneity is large. Our model examines the onset of civil conflict by relating within-group heterogeneity to the effectiveness of negotiations as a way to resolve conflicts. Accordingly, this paper complements Esteban and Ray (2011), who relate within-group heterogeneity to conflict intensity.

\subsection{General Case}

In the previous section, we assumed $\pi_{i}$ is uniformly distributed. This section analyzes the model in more general environments.

Let $f$ and $F$ denote the density and cumulative distribution function of the distribution of $\pi_{i}$. Then the number of opposition group members who support the government offer is given by $1-F(\tilde{\pi}(T))$. For simplicity, assume $p(n)=n \cdot{ }^{13}$ Then, government's problem can be written as

$$
\max _{T} n(T)\left(W_{G}-T\right)+[1-n(T)]\left[(1-C) W_{G}-V_{O}\right] .
$$

\footnotetext{
${ }^{13}$ That is, we assume $\sigma=1$.
} 
From the first-order condition, the optimal level of transfer $T^{*}$ satisfies

$$
n^{\prime}\left(T^{*}\right) R\left(T^{*}\right)=n\left(T^{*}\right) .
$$

The LHS is the marginal benefit the government receives from increasing its offered transfer. It is the product of the increase in the probability of peace and the peace surplus. As seen in the previous section, in the case of a uniform distribution, this marginal benefit declines with within-group heterogeneity. The RHS is the marginal cost of raising the transfer offer. An increase in the offered transfer reduces government's payoff from peace, which is realized with probability $n(T)$.

Equation (22) can be written as

$$
\frac{f\left(\tilde{\pi}\left(T^{*}\right)\right)}{1-F\left(\tilde{\pi}\left(T^{*}\right)\right)}=\frac{1}{R\left(T^{*}\right)} .
$$

The LHS is the hazard rate of the distribution at $\pi_{i}=\tilde{\pi}\left(T^{*}\right)$. Since the RHS is increasing in $T^{*}$, a unique solution exists when the hazard rate function is nondecreasing in $\pi_{i} \cdot{ }^{14}$ Further, if the hazard rate declines with variance in the distribution, the relation between degrees of within-group heterogeneity and risk of civil war is positive. In addition to the uniform distribution analyzed in the previous section, this property holds under, for example, an exponential distribution.

Proposition 4. Let Assumptions 1-3 hold. In the general environment described above, the risk of civil war relates positively to the degree of within-group heterogeneity in the unique equilibrium when the hazard rate function of the distribution of $\pi_{i}, f\left(\pi_{i}\right) /\left(1-F\left(\pi_{i}\right)\right)$, is nondecreasing in $\pi_{i}$ and decreasing in its variance.

\section{Conclusion}

This paper provides a bargaining model of conflict in which government offers an opposition group a transfer to avoid civil war. Members of the opposition group are heterogeneous in income and ideology, which engenders disagreement about accepting the government's offer. We assume the probability that government's offer avoids conflict increases continuously with the number of members who accept the offer. When within-group heterogeneity is large, the number of members who accept government's offer is less responsive to an increase in its amount. In this situation, government must increase its offer substantially to increase support among the opposition. Peace becomes costly for the government, and peace negotiations are prone to breakdown.

${ }^{14}$ Note that $\tilde{\pi}(T)$ is decreasing in $T$. 


\section{Appendix}

\section{Proof of Proposition 1}

Proof. It is suboptimal for government to offer a transfer larger than $T_{G W}$. Therefore, it chooses either offer $T=T_{G W}$ to avoid conflict or offer $T<T_{G W}$ and goes to war. The government offers $T=T_{G W}$ if and only if

$$
W_{G}-T_{G W} \geq(1-C) W_{G}-V_{O} .
$$

The LHS is the payoff government receives by offering $T=T_{G W}$ to avoid conflict. The RHS is government's payoff when conflict occurs. Condition (A1) can be rewritten as

$$
C\left(W_{G}+W_{O}\right)+\bar{\alpha}-\bar{\epsilon} \geq 0 .
$$

By Assumption 1, the LHS of (A2) is positive and, therefore, (A2) always holds.

\section{Proof of Proposition 2}

Proof. Because it is suboptimal for the government to offer a transfer larger than $T_{M}$, it chooses either offers $T=T_{M}$ to avoid conflict or offers $T<T_{M}$ and accepts war. Government offers $T=T_{M}$ if and only if

$$
W_{G}-T_{M} \geq(1-C) W_{G}-V_{O} .
$$

This condition can be rewritten as

$$
C\left(W_{O}+W_{G}\right)+\pi_{m} \geq 0 .
$$

If $\pi_{m} \geq \bar{\pi}$, this condition always holds by Assumption 1. If $\pi_{m}$ is sufficiently small such that $\pi_{m}<-C\left(W_{O}+W_{G}\right)$, government chooses war. The threshold $-C\left(W_{O}+W_{G}\right)$ is decreasing in $C, W_{O}$, and $W_{G}$.

\section{References}

Azam, J.P. (1995). "How to pay for the peace? A theoretical framework with references to African countries." Public Choice, 83(1), 173-184.

Azam, J.P., Mesnard, A. (2003). "Civil war and the social contract." Public Choice, 115(3), 455-475.

Blattman, C., Miguel, E. (2010). "Civil war." Journal of Economic Literature, $48(1), 3-57$. 
Cerra, V., Saxena, S.C. (2008). "Growth dynamics: the myth of economic recovery." American Economic Review, 98(1), 439-457.

Clapham, C. (1998). "Rwanda: the perils of peacemaking." Journal of Peace Research, 35(2), 193-210.

Collier, P., Hoeffler, A. (1998). "On economic causes of civil war." Oxford Economic Papers, 50(4), 563-573.

Collier, P., Hoeffler, A. (2004). "Greed and grievance in civil war." Oxford Economic Papers, 56(4), 563-595.

Dixit, A., Londregan, J. (1996). "The determinants of success of special interests in redistributive politics." Journal of Politics, 58(4), 1132-55.

Eisenberg, L. Z., Caplan, N. (2010) Negotiating Arab-Israeli peace: patterns, problems, possibilities. Bloomington, Indiana University Press.

Esteban, J. Ray, D. (2011). "A model of ethnic conflict." Journal of the European Economic Association, 9(3), 496-521.

Fearon, J. D. (1995). "Rationalist explanations for war." International Organization, 49(3), 379-414.

Fearon, J. D., Laitin, D. D. (2003). "Ethnicity, insurgency, and civil war." American Political Science Review, 97(01), 75-90.

Haimanko, O., Le Breton, M., Weber, S. (2005). "Transfers in a polarized country: bridging the gap between efficiency and stability." Journal of Public Economics, 89(7), 1277-1303.

Jackson, M. O., Morelli, M. (2007). "Political bias and war." American Economic Review, 97(4), 1353-73.

Kydd, A., Walter B. F. (2002). "Sabotaging the peace: the politics of extremist violence." International Organization, 56(2), 263-296.

Lindbeck, A. Weibull, J. (1987). "Balanced-budget redistribution as the outcome of political competition." Public Choice, 52 (3), 273-297.

Miguel, E., Satyanath, S., Sergenti, E. (2004). "Economic shocks and civil conflict: an instrumental variables approach." Journal of Political Economy, 112(4), 725-753.

Mizuno, N., Naito, K., Okazawa, O. (2012). "Inequality, extractive institutions, and growth in nondemocratic regimes." MPRA Paper No. 41434. 
Østby, G., Nordås, R., Rød, J.K. (2009). "Regional inequalities and civil conflict in Sub-Saharan Africa." International Studies Quarterly, 53(2), 301-324.

Persson, T., Tabellini, G.E. (2000). Political economics: explaining economic policy. Cambridge, The MIT Press.

Powell, R. (1999). In The Shadow of Power: States and Strategies in International Politics. Princeton, Princeton University Press.

Powell, R. (2002). "Bargaining theory and international conflict." Annual Review of Political Science, 5(1), 1-30.

Powell, R. (2006). "War as a commitment problem." International Organization, 60(1), 169-203.

Reynal-Querol, M. (2005). "Does democracy preempt civil wars?" European Journal of Political Economy, 21(2), 445-465.

Rodrik, D. (1999). "Where did all the growth go? External shocks, social conflict, and growth collapses." Journal of Economic Growth, 4(4), 385-412.

Staniland, P. (2012). "Between a rock and a hard place insurgent fratricide, ethnic defection, and the rise of pro-state paramilitaries." Journal of Conflict Resolution, 56(1), 16-40. 